\title{
BMJ Open 'It's surprising how differently they treat you': a qualitative analysis of trainee reflections on a new programme for generalist doctors
}

\author{
E Muddiman, ${ }^{1}$ A D Bullock, ${ }^{1} \mathrm{~J}$ MacDonald, ${ }^{2}$ L Allery, ${ }^{2} \mathrm{~K} \mathrm{~L} \mathrm{Webb},{ }^{1}$ L Pugsley ${ }^{2}$
}

To cite: Muddiman E, Bullock AD, MacDonald J, et al. 'It's surprising how differently they treat you': a qualitative analysis of trainee reflections on a new programme for generalist doctors. BMJ Open 2016;6: e011239. doi:10.1136/ bmjopen-2016-011239

- Prepublication history for this paper is available online. To view these files please visit the journal online (http://dx.doi.org/10.1136/ bmjopen-2016-011239).

Received 22 January 2016 Revised 11 May 2016 Accepted 8 June 2016

CrossMark

${ }^{1}$ Cardiff Unit for Research and Evaluation into Medical and Dental Education (CUREMeDE), Cardiff University School of Social Sciences, Cardiff, UK ${ }^{2}$ Cardiff University School of Postgraduate Medical and Dental Education, Cardiff, UK

Correspondence to Dr E Muddiman;

MuddimanEK@Cardiff.ac.uk

\section{ABSTRACT}

Objectives: An increase in patients with long-term conditions and complex care needs presents new challenges to healthcare providers around the developed world. In response, more broad-based training programmes have developed to better prepare trainees for the changing landscape of healthcare delivery. This paper focuses on qualitative elements of a longitudinal, mixed-methods evaluation of the postgraduate, post-Foundation Broad-Based Training (BBT) programme in England. It aims to provide a qualitative analysis of trainees' evaluations of whether the programme meets its intentions to develop practitioners adept at managing complex cases, patient focused care, specialty integration and conviction in career choice. We also identify unintended consequences.

Setting: 9 focus groups of BBT trainees were held over a 12-month period. Discussions were audiorecorded and subjected to directed content analysis. Data were collected from trainees across all 7 participating regions: East Midlands; West Midlands; Severn; Northern; North Western; Yorkshire and Humber; Kent, Surry and Sussex.

Participants: Focus group participants (61 in total) from the first and second cohorts of BBT.

Results: Evidence from trainees indicated that the programme was meeting its aims: trainees valued the extra time to decide on their onward career specialty, having a wider experience and developing a more integrated perspective. They thought of themselves as different and perceived that others they worked alongside also saw them as different. Being different meant benefitting from novel training experiences and opportunities for self-development. However, unintended consequences were feelings of isolation, and uncertainty about professional identity.

Conclusions: By spanning boundaries between specialties, trainee generalists have the potential to improve experiences and outcomes for patients with complex health needs. However, the sense of isolation will inhibit this potential. We employ the concept of 'belongingness' to identify challenges related to the implementation of generalist training programmes within existing structures of healthcare provision.

\section{Strengths and limitations of this study}

- This is the first and only study to explore trainee views on a new generalist programme introduced in England in 2013; it therefore presents a unique opportunity to investigate the real-world experience of a new training programme across multiple regions.

- Given the international nature of the drive for more generalism within the medical profession, our project has wide relevance beyond the specificities of the programme we report on.

- Our directed content approach to analysis allows for the emergence of intended and unintended themes, which we relate to existing theory.

- We acknowledge that not all trainees on the programme participated in focus groups, and so our findings may not fully represent all trainees.

- We recognise the need for a longer term evaluation and the inclusion of other perspectives in addition to those of trainees.

\section{INTRODUCTION}

Ageing populations ${ }^{1}{ }^{2}$ and the increasing prevalence of patients with complex, longterm conditions have widespread implications for the delivery of care, presenting significant challenges for healthcare providers in primary and secondary care. ${ }^{3} 4$ Concerns have been raised about a lack of continuity and overall responsibility for the care of this type of patient ${ }^{5}$ leading healthcare providers to consider alternative arrangements, such as the 'hospitalist' in the USA (a generalist physician responsible for patients throughout their hospital stay $)^{6-8}$ or the Dutch model of care championed at the Erasmus Medical Centre in Rotterdam, where the traditional organisation of care according to medical specialties has been reorganised around the needs of patients with multiple conditions. ${ }^{9}$

Recent years have seen significant developments in UK medical education and training, 
following recommendations identified in key reports. ${ }^{10-12}$ These reports emphasised the need for more broadbased training in order to equip doctors to respond better to the changing needs of patients and the service generally. Recently, the Greenaway review, ${ }^{13}$ an extensive, UK-wide consultation on the Shape of Training was warmly welcomed by the General Medical Council (GMC). ${ }^{14}$ In response the Academy of Medical Royal Colleges (AoMRC) developed a Broad-Based Training (BBT) approach in England. This was a 2-year programme following the 2-year postgraduate 'foundation' training, funded by the Health Education England (HEE). BBT was designed to develop practitioners adept at managing complex cases, patient-focused care, specialty integration and conviction in career choice. It began as a pilot in 2013 and in 2016 was running in most regions (Local Education and Training Boards-LETBs) in England.

BBT provides 6-month placements in general practice (GP), core medical training, paediatrics and psychiatry, and extends the overall training period by 1 year. Trainees begin the programme after completing 2 years of postgraduate foundation training, at the point when they would traditionally be specialising in just one medical discipline. Application to BBT was competitive and follows the same process as application to traditional programmes. There are two main differences between BBT and traditional postgraduate specialty programmes. The first is that trainees would normally have to select one medical specialty after their foundation training, and would not have exposure to other specialty areas in their onward training. In addition, unlike traditional specialty training, the BBT programme has been designed specifically with the intention of fostering interspecialty integration and the development of the skills needed to manage patients with complex care needs. For example, during each placement trainees spend $10 \%$ of their time (equivalent to one morning per week) in another of the four specialties to encourage interspecialty links. After BBT, trainees join the second year of one of these four specialties, meaning that while they have an extra year of training overall, they will have 6 months less experience in their chosen onward specialty. All BBT trainees are expected to develop generic capabilities that reinforce medical professionalism. ${ }^{15} \mathrm{BBT}$ fits with Greenaway's recommendation that postgraduate trainee doctors should have the opportunity to spend up to a year in a related specialism.

We have been commissioned by the AoMRC and funded by HEE to evaluate the programme, exploring whether it meets its aims and better prepares trainees for specialty training and the changing landscape of healthcare delivery.

\section{METHODS}

As part of a mixed-methods longitudinal study, we report on focus group data collected from the first and second intakes of BBT trainees: BBT $2013 \quad(n=42$ at outset) and BBT 2014 ( $\mathrm{n}=30$ at outset). Cohort 1 (BBT 2013) began the programme in August 2013, cohort 2 (BBT 2014) enrolled in August 2014. During the programme, eight trainees left (for maternity or other reasons). Nine focus group discussions (61 participants in total, with 49 unique individuals and 12 trainees participating in more than one discussion) were held at biannual national meetings in London (see table 1). Individual focus groups had between 4 and 10 participants, and lasted between $25 \mathrm{~min}$ and 1 hour (357 min of audio recordings in total).

Participation was voluntary, informed consent was gained and participants are anonymised. We made initial contact with each cohort of trainees in writing prior to the start of the programme to inform them about the aims of the research and the nature of their potential involvement. As external researchers from an independent institution, the principle of neutrality was central to our approach. There was no issue of a power relationship as all researchers had no connection to these trainees in any way. We introduced ourselves to new trainees in person at the national meetings and have maintained regular email contact with all trainees. Our sample was opportunistic, according on attendance at the national meetings. This means that while some trainees will have participated in more than one focus group $(n=12)$, the voices of others, who remain in programme and have not attended any of the national meetings $(n=15)$, remain unheard. Unfortunately, due

Table 1 Focus groups-data collection points

\begin{tabular}{|c|c|c|c|c|}
\hline & May 2014 & November 2014 & May 2015 & $\begin{array}{l}\text { Total } \\
\text { participation }\end{array}$ \\
\hline $\begin{array}{l}\text { BBT cohort } 1 \text { (2013) } \\
n=42 \text { at outset }\end{array}$ & 3 groups $(n=28)$ & $\begin{array}{l}2 \text { groups }(\mathrm{n}=11) \\
\text { including } 5 \text { new } \\
\text { participants }\end{array}$ & & $\begin{array}{l}39 \text { participants } \\
33 \text { unique } \\
\text { individuals }\end{array}$ \\
\hline $\begin{array}{l}\text { BBT cohort } 2(2014) \\
n=30 \text { at outset }\end{array}$ & & 2 groups $(n=11)$ & $\begin{array}{l}2 \text { groups }(\mathrm{n}=11) \\
\text { including } 5 \text { new } \\
\text { participants }\end{array}$ & $\begin{array}{l}22 \text { participants } \\
16 \text { unique } \\
\text { individuals }\end{array}$ \\
\hline $\begin{array}{l}\text { Total trainees } \\
n=72 \text { at outset. } 8 \text { trainees left } \\
\text { programme }(n=64)\end{array}$ & & & & $\begin{array}{l}61 \text { participants } \\
49 \text { unique } \\
\text { individuals }\end{array}$ \\
\hline BBT, Broad-Based Training. & & & & \\
\hline
\end{tabular}


to the wide geographical spread of these remaining trainees and their timetabled commitments, it was not possible to arrange additional focus groups with these trainees. None of the national meeting attendees refused to participate or dropped out of the research project, but the absence of other trainees might be regarded as non-participation.

Focus groups were an appropriate means of gathering data on individual participants' reflections on the programme which they were able to clarify and discuss as a group. ${ }^{16} 17$ At the beginning of the focus group, it was emphasised that the purpose of the discussion was not to reach consensus, but to identify a range of perspectives. To counter the deductive tendency of focus groups, ${ }^{17}$ the question guide included general open questions designed to capture a range of views. Our main objectives were to explore trainee experiences of the BBT programme, including questions about inductions, teaching, training, assessment and onward progression. We also asked how trainees felt BBT was performing in relation to its stated objectives, and sought their views on the shape of future medical provision. We took a 'topical steering' approach to moderating focus groups. ${ }^{18}$ Prior to each data collection session, a briefing meeting was held to ensure consistency of approach, and during focus groups there were opportunities for participants to ask questions about the research and the researcher.

\section{Directed content analysis}

We took a directed approach to content analysis in order to systematically categorise data. ${ }^{19}$ An initial coding frame was developed according to the goals of the BBT programme. The coding frame was developed iteratively and subjected to ongoing concordance tests by three members of the research team independently coding samples of transcription then discussing their coding. The level of concordance was high. The whole team met regularly to discuss the ongoing coding. Data coding was managed using Nvivo V.10. For an abbreviated coding frame, see table 2.

\section{RESULTS}

The distribution of quoted extracts reported aligns with the length of the focus group and number of participants; those focus groups with the most participants, and lasting the longest, tended to provide more of the extracts reported here.

\section{Time to gain a wider perspective}

Gaining a wider perspective was seen by trainees as a central achievement of the BBT programme, and something that they were especially pleased they had developed. Many described having a different or deeper experience of particular specialties compared with their rotations in foundation training. A number of possible reasons for this different experience were discussed: more confidence and maturity, taking on more clinical responsibility, being in a different hospital or unit, and spending longer in each rotation.

Trainees spoke about the value of being encouraged to examine the links between specialties. By moving between the four specialties, trainees described developing broad-based knowledge, learning about the boundaries and cross-overs between specialties, and becoming more holistic practitioners as a consequence:
Table 2 Abbreviated coding frame

\begin{tabular}{lll}
\hline Theme* & Description & Subthemes \\
\hline Time to develop & $\begin{array}{l}\text { Extra time to develop valuable skills } \\
\text { and gain experiences compared } \\
\text { with conventional year one core/ } \\
\text { specialist pathways }\end{array}$ & $\begin{array}{l}\text { Exposure in different specialties } \\
\text { Gaining a wider perspective } \\
\text { Integration between specialties } \\
\text { Questioning links between specialties }\end{array}$ \\
\hline Developing transferrable skills & The development of professional & Taking initiative/responsibility \\
& and transferrable skills during the & Negotiation and compromise \\
& programme & Developing a different mind-set \\
& & Flexibility \\
& & Managing deficits \\
\hline Identity & Issues to do with trainees' identity, & Isolation \\
& how they relate to those on & Fitting in and transition \\
traditional pathways, and feelings of & Needing to justify \\
belongingness and exclusion & Bigger problem for second cohort \\
& & Getting special treatment \\
& Guilt and anxiety \\
& & Benefits to BBT trainees \\
& & Communities of practice \\
\end{tabular}

${ }^{*}$ All three main themes were evident in all nine focus groups.

BBT, Broad-Based Training. 
I think doing the different specialties...it does actually enhance your breadth of knowledge in other areas that perhaps trainees that are fixed in one thing are lacking sometimes. (BBT2013-May-2014-FGA)

It's...an opportunity to really broaden our medical knowledge and to become more of a well-rounded doctor rather than one who is Medicine focussed or one who's just focussing on Psychiatry, and I like the way broad-based just brings all those specialties together. (BBT2014-November-2014-FGA)

It was common for trainees to describe how exposure to different specialties would enhance their practice as a GP:

I've seen things in a completely different perspective having worked in them now...going into GP I'll actually be able to give my patients a very informed understanding of what's going to happen to them, and actually use the services appropriately. (BBT2013-November-2014FGD)

The benefits of this wider perspective were also felt by those intending to pursue hospital-based specialties. Trainees in both cohorts intended to use their experience in psychiatry to be mindful of the emotional as well as physical burdens facing patients encountered elsewhere in the health service:

Going from Psych to Medicine...I feel more equipped for patients coming in...with deliberate self-poisoning or any other mental health conditions on the ward...I've got a better...overall picture of that patient's mind-set and the journey that they might be taking, and what they need having had that kind of psychiatric experience. (BBT2014-May-2015-FGC)

Many commented on how the exposure across the specialties was enabling them to better understand the patient journey through the healthcare system, and fostering a patient-centred approach. Trainees gave examples of picking up 'all the good bits' from one specialty and taking it with them to another to inform best practice (BBT2013-May-2014-FGA). This wider perspective extended to having a greater understanding of the pressures and limitations experienced by colleagues in different specialties and becoming more tolerant as a result:

It helps you understand why some specialties do certain things...you can get really frustrated as to why somebody has done something [but] then having moved to that specialty, you kind of see why. (BBT2013-May-2014-FGA)

They thought that this broader perspective was enabling them to become 'better doctors' (BBT2014November-2014-FGA), and to add value to a specialty team. One example of this was using their wider knowledge in making referrals, which they argued led to greater efficiency and improved patient care. However, some trainees shared concerns that their competence in managing particular medical situations was not always recognised by those around them, and that this 'limited' their ability to act:

Although you might feel that...you could manage this, actually the people around you won't. (BBT2013November-2014-FGD)

Additionally, some trainees questioned the link between some specialties on the BBT programme, and argued that this breadth of knowledge would be more appropriate in some specialties than others.

Paediatrics links very well with General Practice but it doesn't link very well with either of the other two. (BBT2013-May-2014-FGC)

\section{Developing transferrable skills}

Since at the time of the data collection BBT was a new programme, there were few existing organisational structures in place and many people with whom trainees liaised had no prior experience of BBT. This contributed to trainees playing a key role in organising their own learning experiences. While taking responsibility for aspects of their own learning and assessment was described by some as frustrating and unsettling-especially when managing deficits in required competencies —it was also viewed as an opportunity for personal development:

Although it can be stressful and it's been difficult I've found I've actually probably gained a lot by having to kind of negotiate these sorts of things, and network with people. (BBT2013-May-2014-FGB)

In addition to allowing them extra time to decide on an onward career specialty and developing a wider perspective, it was common for trainees to argue that BBT had allowed them to develop the transferrable skills that would help them to flourish in the future:

You pick up all the sort of skills that you need later on in your career. So organisation, management, leadership... and you have a longer time to develop these skills. (BBT2013-May-2014-FGB)

Trainees in both cohorts reflected that they had become more proactive, confident and able to use their initiative to negotiate with others (both senior staff and fellow trainees) to reach a compromise, and learning to be flexible was highlighted as a potential asset to healthcare provision.

\section{Being different}

Being perceived differently made some trainees feel special or unique: 'everybody wants to talk to you about it' (BBT2013-May-2014-FGB). In particular, they valued having the time and space to pursue novel training experiences. One trainee suggested that BBT trainees were regarded highly by trainers: "they say 'oh broad 
based trainees, you're a very high class of trainee'" (BBT2013-May-2014-FGB). However, both cohorts identified lack of knowledge about the programme among their colleagues as a problem. Some said that they were incorrectly labelled as 'just a GP trainee' (BBT2013-November-2014-FGD), while others thought that it was difficult for those around them to understand 'what kind of level' they were (BBT2014-November2014-FGA).

A group of cohort 2 trainees (May-2014-FGC) said that the additional training opportunities they were afforded as BBT trainees often caused complications. In particular, the provision for $10 \%$ time was seen as a possible source of conflict, with both senior and junior staff questioning the legitimacy of their absence:

Some of us have found it hard...to organise with each specialty blaming the other...the GP opinion was that Medicine weren't being very lenient...but then Medicine were saying the GPs weren't being very accommodating. So I was sat in the middle. (BBT2014-May-2015-FGC)

I get a lot of resentment for taking the $10 \%$ time...[it] has been educationally great, but they basically were blaming me for not being on the ward...juniors were being resentful towards me. (BBT2014-May-2015-FGC)

This 'lack of understanding' led some trainees to feel 'guilty' about their $10 \%$ time, seeing it as a 'privilege' not afforded to regular trainees (BBT2014May-2015-FGC). Others felt less conflicted about their entitlement to $10 \%$ time as an 'essential' and compulsory element of their programme: "this is my time, I'm going to use it...I don't care whether they resent it or not" (BBT2014-May-2015-FGC). Trainees were quick to point out that issues arising from their $10 \%$ time were related to systems rather than individual people:

They're very helpful as actual people...but the practicalities...when you take the time off they're annoyed that you're not there. (BBT2014-May-2015-FGC)

In order to rectify some of these issues, one trainee called for 'a wider understanding of what BBT actually is' in order to 'champion a better understanding of the importance of the $10 \%$ time rather than trying to, kind of, excuse it' (BBT2014-May-2015-FGC).

\section{Isolation and identity issues}

Being different also led to feelings of isolation. It was common for trainees to argue that they felt particularly isolated during their $10 \%$ time either because of a lack of support, or not having sufficient time to establish relationships with others:

I just turned up...sat there and did the clinic and left... you were so unsupported, like you didn't know anybody...you were only there half a day a week. (BBT2013-May-2014-FGA)
Trainees also reported feeling isolated from one another: with most LETBs only enrolling four trainees per cohort, often on different placements spread across wide geographical areas, trainees explained that they had minimal opportunities to meet and consolidate their experiences of being on the same programme:

Two of us are in [City A] and two of us are in [City B], so we never meet...we won't see each other...its very isolating. (BBT2013-May-2014-FGC)

Not having regular meetings with other broad-based trainees, and spending the majority of time with those on traditional specialist programmes led to feelings of uncertainty about identity:

I don't feel like I'm BBT...because I'm going to so much teaching in Core Medical Training. (BBT2014November-2014-FGA

You just feel like you're completely just a black sheep in the herd. (BBT2013-November-2014-FGD)

This seemed to be compounded by a sense of not fitting in with trainees on traditional programmes. For example, one trainee described feeling 'a little bit as an outsider' as a BBT trainee compared with colleagues in GP who had 'a real sense of community together' (BBT2014-November-2014-FGB). Another trainee described a division in paediatrics between those who had committed to that specialty and those who had not:

In Paediatrics...it's surprising how differently they treat you...like you're second class...because you're not that specialty. (BBT2013-November-2014-FGD)

This led another trainee in the same discussion to describe the division between broad-based and traditional trainees as a 'stigma'. Other trainees shared experiences of being 'overlooked for procedures' (BBT2013-November2014-FGD). This seemed to be specialty-dependent, and appeared to be less of a concern among cohort 2 trainees in departments that had trainees from the first cohort of BBT.

\section{DISCUSSION}

\section{Spanning boundaries}

In this section we draw on social learning theory, and in particular, the concepts of boundary spanning and belongingness, to consider trainee accounts in relation to existing sociological literature. Participants in this study expressed the view that the BBT programme fosters a wider perspective and sense of specialty integration that trainees believe enhances their ability to manage complex cases. In this sense, these trainees span boundaries between specialties. Those in a generalist role might helpfully be thought of as boundary spanners - doctors who reach across 'structural holes' to aid the flow of knowledge about a patient's care between 
previously poorly connected disciplines. ${ }^{20}$ Boundary spanners can play an increasingly important role in the healthcare setting, addressing the challenge of silo working and professional tribalism. ${ }^{21-23}$

Trainees in our study described using a form of 'vision advantage'-defined as the ability to synthesise different approaches and viewpoints and carry them across boundaries ${ }^{24}$ - to enhance patient care. By considering the psychological, as well as physical needs of the patient, these trainees felt that they were able to take a holistic approach that appreciated the whole patient journey, rather than a discrete part of it. This has obvious benefits for the care of patients with complex health needs, and is in tune with the generalist approach advocated by Greenaway. ${ }^{13}$ Trainees also used this broad-based insight to alter both their referral behaviours and to share 'best practice' with colleagues in different specialties. If carried forward, this could benefit the health service by enhancing standards of care and improving efficiency. The communication and negotiation skills that trainees described developing also aid boundary spanning by breaking down silos. In fostering greater understanding and tolerance between doctors in different specialties and challenging the 'homophily' or introspective rigidity of established groups, ${ }^{25}$ these broad-based trainees could also contribute to conflict resolution across cultural (disciplinary) boundaries. ${ }^{26}$

However, there are a number of issues which may limit the success and scope of this boundary spanning activity. First, it is notable that the knowledge and experience of BBT trainees was not always recognised or legitimised by those around them. As a result, trainees described being 'limited' by colleagues who did not trust in their ability to take responsibility for certain medical decisions. Converting human capital (broad-based knowledge) into social capital (the trust and respect of colleagues) therefore seems to be an issue. Existing literature suggests that networks rich in 'structural holes'-like healthcare systems with their hierarchical and highly subdivided departments, disciplines and specialty areas -are not well suited to diffusing and integrating the ideas emanating from boundary spanners. ${ }^{20}$ In addition, the 'sparse' or thin spread of BBT trainees across healthcare networks, both geographically and in terms of their dilution among much larger groups of trainees on traditional specialty programmes may inhibit their role as 'key nodes' in the network. ${ }^{27}$ It may therefore be the case that existing organisational structures will act as barriers to breaking down professional silos. Another challenge pertains to the ability of these trainees to maintain boundary-spanning links over time, especially as they move into their onward specialty training. This is challenging both in terms of intellectual capacity-keeping up with the rate of new knowledge production across specialty areas, and in terms of relational capacitymaintaining cross-boundary relationships or 'bridging ties' with individuals or groups. Existing research suggests that bridging ties with those who are different or distant require more effort to maintain than those close to the individual ${ }^{20}$ and are quicker to decay. ${ }^{28}$

\section{Identity trouble and belongingness}

Our analysis makes clear that being different, developing broad-based knowledge and acting as bridges across specialty boundaries also entails costs for trainees, in the shape of experiences of isolation and uncertainty about professional identity. One potential cost of boundary spanning across two overlapping groups (medical specialty areas) is that the spanner does not fit neatly into one camp or the other. It is interesting that BBT trainees' $10 \%$ time, was identified as both one of the most valuable elements of the programme, and also the most problematic. The $10 \%$ time appears to be vital to the development of a wider perspective, but most troubling for identity development. Only those on the BBT programme are entitled to $10 \%$ time, which marks them out as inescapably different as the recipients of 'special treatment'. The intraprofessional division of labour between doctors has often been overlooked in the medical sociology literature, but existing research suggests that moves to reconfigure the responsibilities of professional groups to provide more joined up services have been met with resistance from the clinical workforce eager to protect their own jurisdictions. ${ }^{29}$ It may therefore be the case that the new training roles discussed in this paper are perceived as a threat to existing medical roles.

Existing research suggests that experiences of isolation in educational settings may inhibit opportunities for learning. In their study of nurses on clinical placements, Levett-Jones and Lathlean ${ }^{30}$ found that a sense of belonging was linked to nursing students' 'self-concept, degree of self-efficacy, the extent to which they were willing to conform with poor practice and future career decisions'. Moreover, the degree to which nursing students felt that they belonged during clinical placements influenced their capacity and motivation to engage in clinical learning opportunities. For example, students felt 'more empowered' and confident to seize learning opportunities when they felt recognised and supported by those around them. Conversely, an absence of belongingness-at worst, alienation-impacted negatively on students' attitudes towards learning and the level of confidence with which they approached experiential learning opportunities. Professional identity formation has also been shown to affect undergraduate medical students' own sense of well-being and their ability to develop positive relationships with colleagues and patients. ${ }^{31}$ However, work is lacking in the postgraduate arena and it is important to recognise that factors outside of education and training will also shape professional identity. ${ }^{32}$

The concept of belongingness ${ }^{30}$ provides a useful lens through which to interpret the experiences of the trainees in our study. If we accept that 'clinical environments that provide students (or trainees) with a feeling 
of security and acceptance empower and enable them to make the most of the learning opportunities presented, ${ }^{30}$ then the experiences of isolation and stigma felt by trainees on the BBT programme are problematic. If trainees feel like 'black sheep' in the clinical environment, this may inhibit their potential for effective learning. This is especially pertinent given that BBT trainees will have 6 months less training in their chosen specialty compared with those on traditional pathways. More troubling is research suggesting that anxiety caused by a diminished sense of belonging may, in the short-term, impair cognitive performance. ${ }^{33}$ However, although being marked out as different could undermine trainees' self-perceptions, this difference also enabled trainees to benefit from novel training experiences that they were confident would make them 'better doctors'. The potential for discomfort is an important element of being part of something different, new and potentially 'better'. The BBT programme offered both opportunities and challenges for trainees in terms of successfully developing their own professional identity and a sense of belonging among colleagues.

Through the focus group discussions, participants had the opportunity to share and discuss ideas and experiences. This approach was particularly valuable when considering some of the commonalities and differences in trainee experiences and helped us to identify priorities and concerns. Our directed content approach allowed for the emergence of inductive and deductive themes, which enabled us to be responsive to the data while grounding our analysis in existing theory. We acknowledge that not all trainees participated in focus groups; one of the limitations of this research therefore is that it may not represent the voices of all those on the BBT programme. In addition, the views and experiences of trainees provide an important but ultimately partial insight into the BBT programme, we therefore recognise the need for a longer term evaluation and the inclusion of other methods and perspectives.

\section{CONCLUSIONS}

Our data suggest that BBT was achieving many of its stated aims. Trainees valued wider experience and developing a more integrated perspective. Those with a broader base to their training experience may go on to benefit the healthcare system in a number of important ways. Trainee accounts of developing a wider perspective suggest that it has the potential to benefit patients (by being mindful of the patient journey and providing holistic care); colleagues in other specialties (by becoming more tolerant) and the healthcare service (by sharing best practice across specialty boundaries and using the referrals system more appropriately). This is especially relevant in the UK context in which concerns have been raised about a lack of continuity and overall responsibility for the care of increasing numbers of patients with complex care needs. ${ }^{5}$ However, the extent to which these trainees can embed their broad-based understandings and integrate them into wider, established practices is currently unclear and will be an important focus for our ongoing investigation.

Our analysis also provides an insight into the challenges inherent in this type of programme. Being different led to feelings of isolation and uncertainty about professional identity. Some existing literature suggests that a lack of belonging may be detrimental to effective learning. We suggest that feeling different is construed as both a benefit and a cost of the BBT programme by trainees. This raises some important questions about the status and identity of the generalists described by Greenaway in the Shape of Training, ${ }^{21}$ and is something that requires further study.

Twitter Cardiff Unit for Research and Evaluation into Medical and Dental Education at @CUREMeDE

Acknowledgements The authors gratefully acknowledge the funding from Health Education England (HEE) and the continued support of the Academy of Royal Medical Colleges (AoMRC) in commissioning our evaluation of the Broad-Based Training programme. Without this award the authors would not have been able to undertake the important study from which this paper draws. The authors would like to extend their gratitude to all of the study participants who have given their time. They are also grateful of first class project support from Cardiff Unit for Research and Evaluation into Medical and Dental Education (CUREMeDE) team members Elaine Russ and Suzanne Phillips.

Contributors All authors contributed substantively to the development of the research instruments (focus group schedules) and each has undertaken at least one of the focus groups reported on in this study. EM, JM and LA developed the coding framework and agreed an analytical strategy with the oversight of project director ADB. EM and ADB drafted the paper. LP, LA, KLW and JM made critical revisions and suggestions for additional literature. All authors have given their final approval of the version to be published and all have agreed to be accountable for all aspects of the work including any issues related to accuracy or integrity.

Funding This work was commissioned by the AoMRC and funded by HEE.

Competing interests None declared.

Ethics approval Research ethical approval was obtained from Postgraduate Medical and Dental Education Ethics Committee, Cardiff University, UK (02/ 10/2013).

Provenance and peer review Not commissioned; externally peer reviewed.

Data sharing statement No additional data are available.

Open Access This is an Open Access article distributed in accordance with the Creative Commons Attribution Non Commercial (CC BY-NC 4.0) license, which permits others to distribute, remix, adapt, build upon this work noncommercially, and license their derivative works on different terms, provided the original work is properly cited and the use is non-commercial. See: http:// creativecommons.org/licenses/by-nc/4.0/

\section{REFERENCES}

1. Wait S, Harding E. The state of ageing and health in Europe. London, UK: International Longevity Centre, 2006.

2. World Health Organisation. Global health and aging. Washington DC: World Health Organisation, 2011.

3. Ham C, Dixon A, Brooke B. Transforming the delivery of health and social care: the case for fundamental change. London, UK: The Kings Fund, 2012.

4. Barnett K, Mercer SW, Norbury M, et al. Epidemiology of multimorbidity and implications for health care, research, and medical education: a cross-sectional study. Lancet 2012;380:37-43. 
5. Royal College of General Practitioners. Guiding patients through complexity: modern medical generalism. London: RCGP, 2011.

6. Wachter RM, Bell D. Renaissance of hospital generalists. BMJ 2012:344:e652.

7. Moizuddin M, Quresh Q, Raza Q. The revolution in inpatient care: hospitalist programme. BJMP 2009;2:20-2.

8. Williams MV. The future of hospital medicine: evolution or revolution? Am J Med 2004;177:446-50.

9. KPMG International. Something to teach, something to learn: global perspectives on healthcare. KPMG International Cooperative, 2013.

10. Tooke J. Aspiring to excellence: findings and final recommendations of the independent inquiry into modernising medical careers. London, UK: MMC Inquiry, 2008.

11. Temple J. Time for training: a review of the impact of the European working time directive on the quality of training. London: NHS Medical Education England, 2010.

12. Collins JP. Foundation for excellence: an evaluation of the foundation programme. London, UK: Medical Education England, 2010.

13. Greenaway D. Shape of training: securing the future of excellent patient care. London: Shape of Training, 2013.

14. Rubins P. Responding to the final report from Professor David Greenaway's Shape of Training Review. GMC Statement 23/10/13. [Online]. 2013. http://www.gmc-uk.org/news/23533.asp (30 Apr 2014].

15. Academy of Medical Royal Colleges in collaboration with RCGP/ RCPCH/JRCPTB/RCPSYHC. Curriculum for a broad based training programme. London: AoMRC, 2012.

16. Curtis B, Curtis C. Social research: a practical introduction. London: Sage, 2011.

17. Brannen J, Pattman R. Work-family matters in the workplace: the use of focus groups in a study of a UK social services department Qual Res 2005;5:523-42.

18. Flick U. An introduction to qualitative research. London: Sage, 2006.

19. Hsieh HF, Shannon S. Three approaches to qualitative content analysis. Qual Health Res 2005;15:1277-88. kers and boundary spanners in.
20. Long JC, Cunningham FC, Braithwaite J. Bridges, bro collaborative networks: a systematic review. BMC Health Serv Res 2013;13:158.

21. Braithwaite J. An empirical assessment of social structural and cultural change in clinical directorates. Health Care Anal 2006;14:185-93.

22. Braithwaite J, Westbrook M. Rethinking clinical organisational structures: an attitude survey of doctors, nurses and allied health staff in clinical directorates. J Health Serv Res Policy 2005;10:10-17.

23. Braithwaite J. Between-group behaviour in health care: gaps, edges, boundaries, disconnections, weak ties, spaces and holes. A systematic review. BMC Health Serv Res 2010;10:330.

24. Burt RS. Structural holes and good ideas. Am J Sociol 2004;110:349-99.

25. Burt RS. Brokerage and closure: an introduction to social capital. New York: Oxford University Press, 2006.

26. Di Marco MK, Taylor JE, Alin P. Emergence and role of cultural boundary spanners in global engineering project networks. J Manag Eng 2010;26:123-32.

27. Rogers E. Diffusion of innovations. 4th edn. New York: Free Press, 2003.

28. Burt RS. Bridge decay. BMC Health Serv Res 2002;24:33-363.

29. Martin GP, Currie G, Finn R. Reconfiguring or reproducing intra-professional boundaries? Specialist expertise, generalist knowledge and the 'modernization' of the medical workforce. Soc Sci Med 2009;68:1191-8.

30. Levett-Jones J, Lathlean J. Belongingness: a prerequisite for nursing students' clinical learning. Nurse Educ Pract 2008;8:103-11.

31. Monrouxe LV. Identity, identification and medical education: why should we care? Med Educ 2010;44:40-9.

32. Cruess RL, Cruess SR, Boudreau JD, et al. A schematic representation of the professional identity formation and socialization of medical students and residents: a guide for medical educators. Acad Med 2015:90:718-25.

33. Baumeister RF, Twenge JM, Nuss CK. Effects of social exclusion on cognitive processes: anticipated aloneness reduces intelligent thought. J Pers Soc Psychol 2002;83:817-27. 